\title{
The ultrasonic burnishing of cobalt-chrome and stainless steel surface made by additive manufacturing
}

\author{
Mika Salmi $^{1} \cdot$ Juha Huuki $^{2}$ - Iñigo Flores Ituarte ${ }^{1}$
}

Received: 16 December 2015 / Accepted: 14 March 2017 / Published online: 29 March 2017

(C) Springer International Publishing Switzerland 2017

\begin{abstract}
The purpose of this paper is to investigate the post-processing of $\mathrm{Co}-\mathrm{Cr}$ and $316 \mathrm{~L}$ stainless steel components made by additive manufacturing (AM) using ultrasonic burnishing. AM is able to produce functional parts for medical and industrial applications; however, the parts require support removal and post-processing to achieve the technical requirements. To this end, ultrasonic burnishing is a formative method used to improve surface quality and increase surface hardness. The aim of this work is to characterize the effect of process variable (e.g. machine and workpiece relative displacements and spring compression) in the surface quality of AM burnished materials. Two separate design of experiments were performed to find optimal values for the process parameters. The analysis of the experimental result was performed using "Minitab 16" statistical software. To this end, an analysis of variance (ANOVA) was performed to study the effect and interactions of process parameter on the final surface quality. The results showed that surface roughness $(\mathrm{Ra})$ was decreased to $0.18 \mu \mathrm{m}$ for as-built $\mathrm{Co}-\mathrm{Cr}$ and $0.55 \mu \mathrm{m}$ for asbuilt $316 \mathrm{~L}$ stainless steel. In addition, the relative increase in average hardness from as-built $\mathrm{Co}-\mathrm{Cr}$ was $47.4 \%$ (i.e. $551.07 \mathrm{Hv}$ ) and $70.7 \%$ from as-built 316L stainless steel (i.e. $338.17 \mathrm{Hv}$ ). The optimal process parameters for post-processing Co-Cr material are around $0.05 \mathrm{~mm} / \mathrm{r}$ for the feed and $1.5 \mathrm{~mm}$ for the spring compression, whereas
\end{abstract}

Mika Salmi

mika.salmi@aalto.fi

1 Department of Mechanical Engineering, School of Engineering, Aalto University, Otakaari 4, 02150 Espoo, Finland

2 Department of Mechanical Engineering, School of Engineering, Aalto University, Puumiehenkuja 3, 02150 Espoo, Finland post-processing of $316 \mathrm{~L}$ requires $1000 \mathrm{~mm} / \mathrm{min}$ for the feed speed, $0.025 \mathrm{~mm}$ for the side shift and $1 \mathrm{~mm}$ for spring compression, when taking also productivity into consideration. The results of this experiment show that the subtractive methods and labour-intensive post-processing of AM metal parts can be replaced by burnishing methods, thus reducing the cost barriers of additive technology and drive its adoption in industry.

Keywords 3D printing - Additive manufacturing - Postprocessing - Direct metal laser sintering (DMLS) · Microhardness $\cdot$ Surface quality

\section{Introduction}

The post-processing of additively produced components has been identified as one of the bottlenecks for technology transferability [1, 2]. Previous research [3] and roadmaps in the field of additive manufacturing (AM), such as Horizon 2020 [4], identified that the geometrical stability and surface quality of AM metal components have to be improved to reach the high requirements of engineering applications. Therefore, automated mechanical post-processing techniques based on formative or subtractive methods are required to meet the engineering requirements and make the technology cost-effective for industries, such as the aerospace, automotive and medical industries. Research in the field now focuses on finding and testing new methods to automate and improve the post-processing of the surfaces of AM processes [5].

In this regard, the aim of this study is to characterize the performance of ultrasonic burnishing as an automated finishing strategy for AM produced metal components (i.e. cobalt-chrome and stainless steels). Research presented 
by Mahajan and Tajane [6] shows how burnishing can improve the surface quality of metal workpieces. The process itself consists of pressing feed motion hardened steel rolls or balls into the surface of the workpiece being postprocessed. Ultrasonic burnishing works at high impact frequencies (over 20,000 impacts per second can be achieved [7]), and industry typically uses this technique to finish conventionally produced metal surfaces.

However, up-to-date results of ultrasonic burnishing in AM produced materials has not been presented. Hence, there is a need to explore this process as a post-processing strategy for AM produced metal components. This research presents new empirical data of AM burnish materials and the technique's comparison with traditional subtractive strategies, presenting the results in terms of surface hardness and surface quality. In relation to subtractive post-processing techniques, burnishing processes might also provide advantages. As presented by Hassan and Al-Bsharat [8], burnishing increases the surface hardness of the workpieces, which improves wear resistance. It also increases corrosion resistance and improves fatigue strength by inducing residual compressive stresses in the surface of the workpieces.

It not only treats material on the surface efficiently but also deforms it locally, producing compressive residual stresses in the treated workpieces [9]. A positive effect of ultrasonic burnishing is that the use of lubricants and cooling fluid are limited compared to subtractive processes [10]. The previous research results of conventionally produced materials show that for aluminium, 34-CrNiMo6 tempering steel and S355J2 structural steel, burnishing increased the hardness of the surface by up to $13.5 \%$ and decreased surface roughness by $88 \%$ when compared to the raw material [11]. Many other materials, such as deep cold rolled aluminium and steels, have been processed at higher pressure, obtaining higher hardness values but lower surface qualities [12].

Hocheng and Kuo [5] have reported that burnishing methods are suitable for processing plane-shaped geometries, and El-Khabeery and El-Axir [13] applied the same technology to process curved and double curved surfaces. In this regard, AM technologies are optimal for producing the organic geometries used in dental and medical applications [14] and additively produced $\mathrm{Co}-\mathrm{Cr}$ implants have huge potential in the dental field, having the drawback of low surface quality directly after manufacturing [15].

In the case of industrial applications, mechanical postprocessing techniques, such as shoot blasting or subtractive milling processes, are typically used to finish and improve the surface quality of AM-produced tools [16]. For instance, stainless-steel tool inserts for plastic injection moulds, as well as tool inserts for the hot spots of forming tools in automotive applications, are being produced using
AM metal systems [17]. Typically, sequential Numerical Control (NC) milling is always required to achieve the geometrical requirements [18]. AM technology is also suitable for the reparation of aircraft engine parts, such as turbine blades, as well as suitable for the production of complex parts for end-use applications [19]. However, AM-produced or repaired components will still require post-processing, which is mostly performed by NC machining of the remanufactured part [20].

In both medical and industrial applications, the surface quality of AM parts is often a barrier and mechanical post-processing is often required [21], making the AM alternative even more costly. Nevertheless, by automating the post-processing of AM parts the use of this technology could become more cost effective and technically suitable for its final use. Therefore, the further study of ultrasonic burnishing for the post-processing of AM metals is interesting since the ultrasonic burnishing tool can be installed in conventional NC machines to improve surface quality and hardness.

\section{Material and experimental methods}

In literature, there is no previous data about burnishing parameters for any AM materials or traditional Co-Cr. To this end, the experiment started using round $\mathrm{Co}-\mathrm{Cr}$ samples and lathe as holder for the tool. Since AM parts are very rare simple as tube and based on results from $\mathrm{Co}-\mathrm{Cr}$ samples, machining centre was selected for more complex testing. The material tested was changed to $316 \mathrm{~L}$ steel since there was more data and parameters about burnishing traditional steels and possible wider application field.

\subsection{The additive manufacturing process}

During the AM process, six test shafts were manufactured from EOS Cobalt Chrome SP2 (Co-Cr) powder using EOSINT M 270 equipment with default parameters and a layer thickness of $20 \mu \mathrm{m}$. The default parameters involved a scan speed of $1100 \mathrm{~mm} / \mathrm{s}$, laser spot size of $0.1 \mathrm{~mm}$, hatch spacing $100 \mu \mathrm{m}$ and a maximum power output of $195 \mathrm{~W}$. During the AM process, the test shafts were oriented horizontally; hence, all tested surfaces are side surfaces since the top surface already has much better surface quality and only the bottom surface required support removal. Typically, in Co-Cr materials, the average surface hardness asmanufactured is approximately $360 \pm 20 \mathrm{HV} 10$ and surface roughness Ra $8 \mu \mathrm{m}$ and Rz 30-50 $\mu \mathrm{m}$ [22].

In addition, four hexagonal prims were manufactured from EOS Stainless-steel 316L powder with 12 test surfaces on each. In this case, the machine was an EOSINT M 280 with default manufacturing parameters and a layer 
thickness was $20 \mu \mathrm{m}$. These parameters involved a scan speed of $900 \mathrm{~mm} / \mathrm{s}$, laser spot size of $0.1 \mathrm{~mm}$, hatch spacing $100 \mu \mathrm{m}$ and a maximum power output of $195 \mathrm{~W}$. No heat treatments or stress relieving were implemented. The $316 \mathrm{~L}$ has high ductility and corrosion resistance and is used in applications such as jewellery making, tooling and manufacturing applications, as well as in the medical field and in aerospace. Typical hardness as-manufactured is $170 \mathrm{HV} 10$ and surface roughness Ra $13 \pm 5 \mu \mathrm{m}$ and $\mathrm{Rz}$ 30-50 $\mu \mathrm{m}$ [22]. During the AM process, all 316L hexagonal prims we oriented horizontally, according to the same principle as that of the test shafts. In this regard, Fig. 1 shows the processed test pieces after the ultrasonic burnishing process.

These materials were selected due to their potential real applications, such as in medical manufacturing or tooling industry. As mentioned earlier, the additively produced and burnished high performance steel can be used for tooling applications and $\mathrm{Co}-\mathrm{Cr}$ can be used in dental applications. Previous studies have characterized the ultrasonic burnishing of aluminium, tempered steel and its alloys, polymers, titanium, brass, nickel and copper [6]. However, additively produced materials have not been studied in depth and the chosen materials require characterization after the ultrasonic burnishing in order to study its suitability in the presented industrial contexts.

\subsection{The experimental setup and the ultrasonic burnishing process}

The ultrasonic burnishing equipment was installed first to a manual lathe to process the $\mathrm{Co}-\mathrm{Cr}$ cylindrical parts (see Fig. 2a). On the other end, the same equipment was installed to process the $316 \mathrm{~L}$ stainless steel prims using a NC machining centre (see Fig. 2b). The response variables for both experiment were surface roughness (Ra), and hardness values (Hv10) were measured for the most relevant results. The experiment had the objective to characterize surface roughness by means of ultrasonic burnishing of AM-produced metallic materials.

As an overview of the ultrasonic burnishing process, the finishing head is compressed against the test piece where the spring ensures constant contact. In addition, lubrication fluid is added between the finishing head and the work piece. The frequency can be controlled via the control unit. Both experimental setups (i.e. Co-Cr lathe processing and 316L milling processing) were connected to the same generator and control unit. Figure 3 shows a schematic of
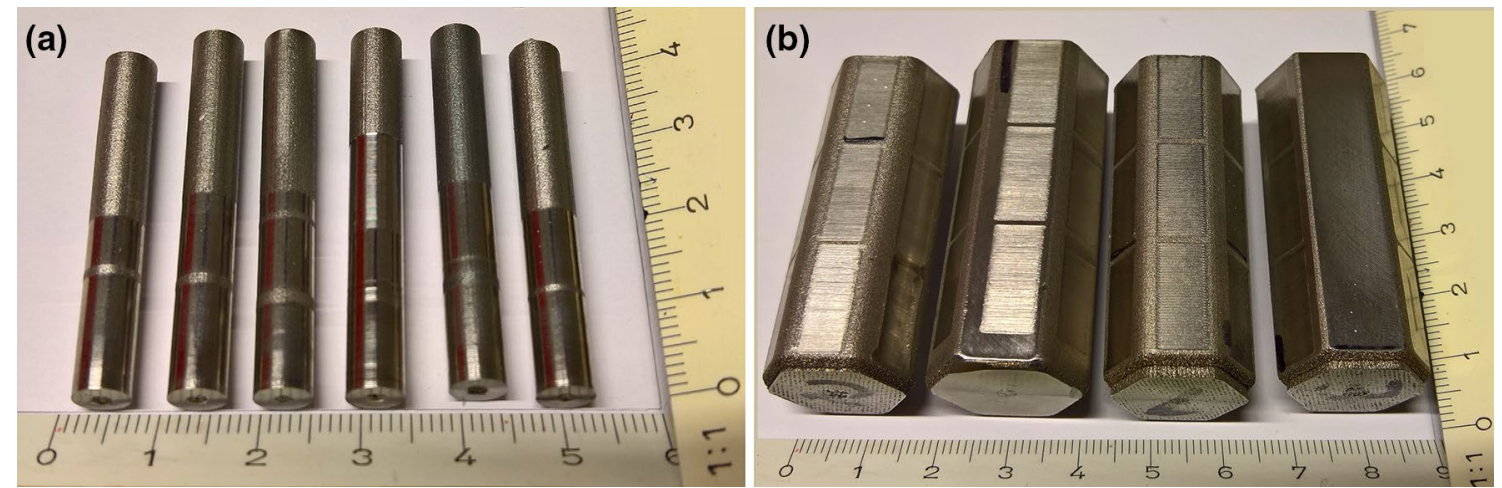

Fig. 1 a Co-Cr cylindrical test samples. b 316L Stainless steel prims. Images of the test pieces after ultrasonic burnishing
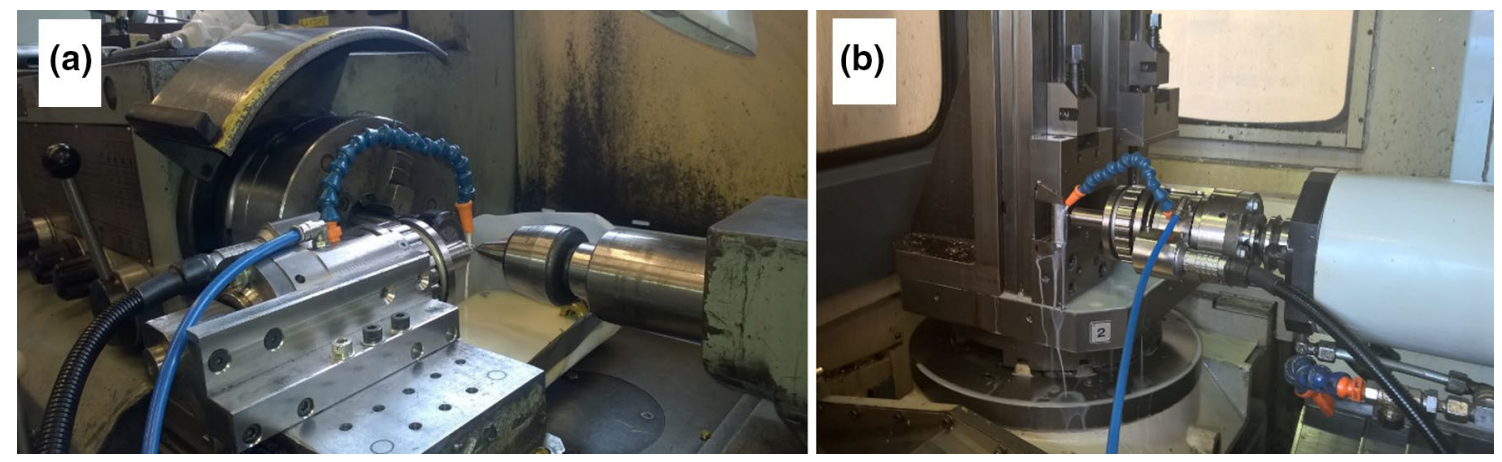

Fig. 2 a The ultrasonic burnishing equipment installed into a manual lathe. b The equipment installed in NC machining centre 
A

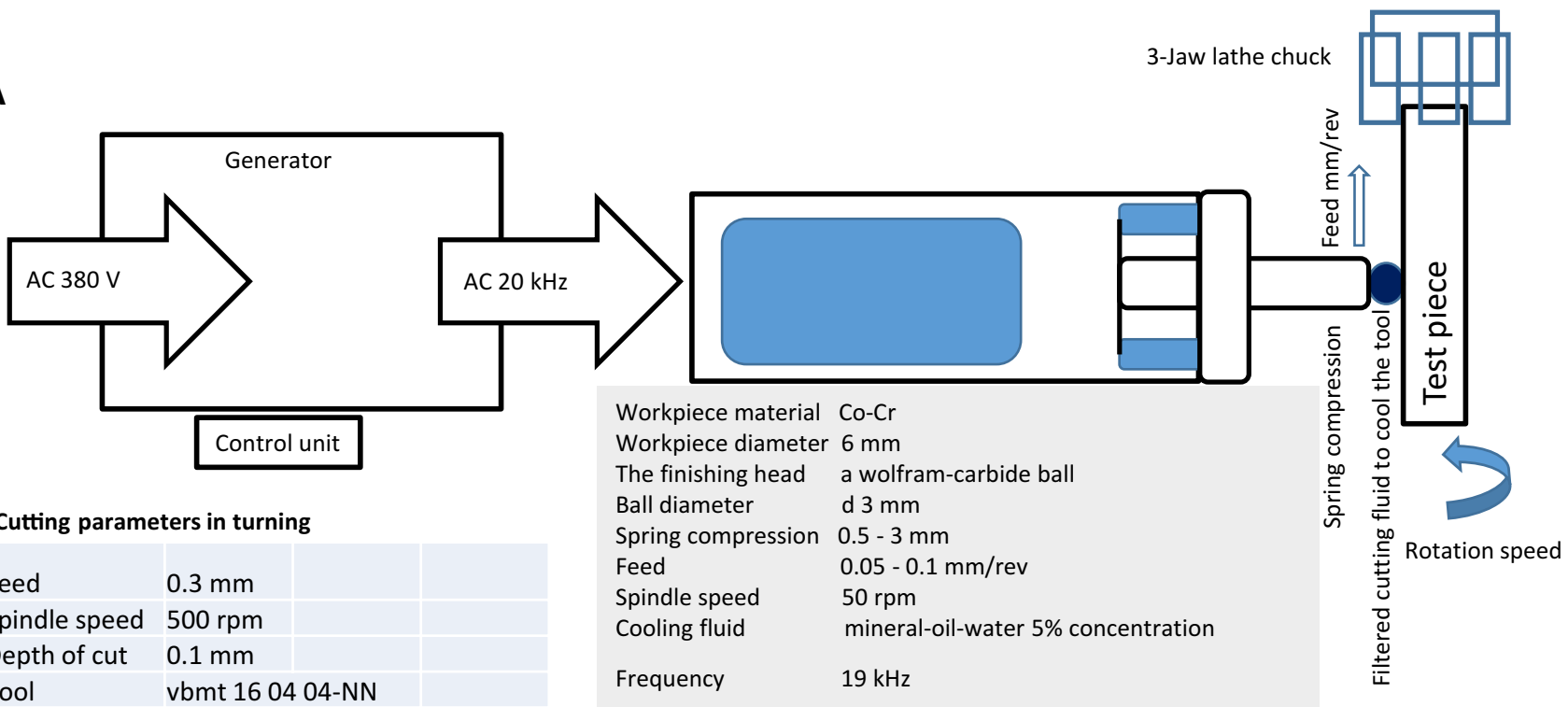

Tool vbmt 1604 04-NN

B
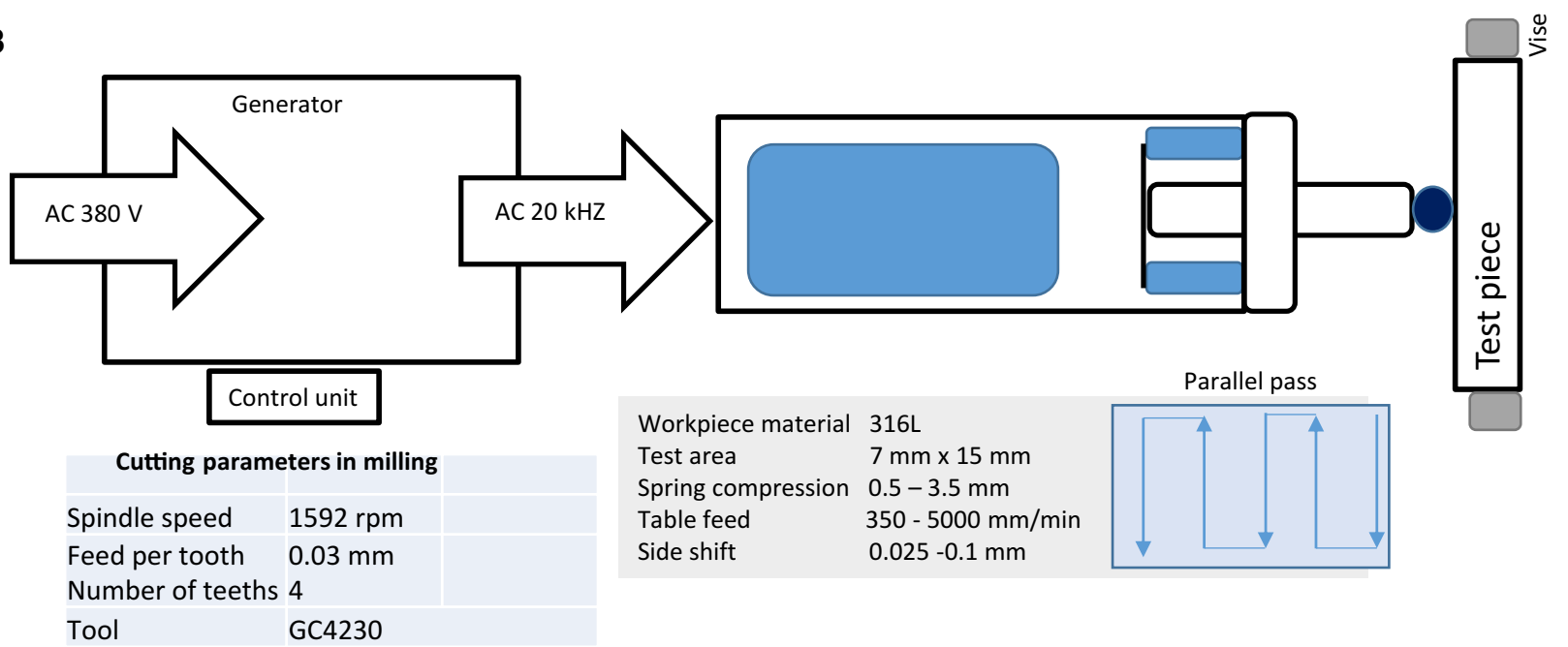

Tool

GC4230

Fig. 3 The schematic of the ultrasonic burnishing system - the measurements and data acquisition process. a Co-Cr lathe processing and $\mathbf{b}$ 316L milling processing

the process as well as the detail of the process parameter involved in the experimental work.

To process the Co-Cr, we used a manual lathe with a spindle power of $11 \mathrm{~kW}$. The burnishing was performed with the HIQUSA ultrasonic burnishing equipment, with a wolfram-carbide ball with a 3-mm diameter. Looking at the previous body of knowledge [6], the experiment required to fix some of the process parameters; these involved a spindle speed of $50 \mathrm{rev} / \mathrm{min}$ with an impact frequency of $19,000 \mathrm{~Hz}$. This initial experiment plan involved a full factorial design of experiment (DOE) to obtain reference values. This was performed by studying two relevant factors: (1) feed (mm/rev) and (2) spring compression (mm). Feed had 2 levels (i.e. $0.05 \mathrm{~mm} / \mathrm{rev}$ and $0.1 \mathrm{~mm} / \mathrm{rev}$ ) and spring compression was tested for 7 levels (i.e. ranging from 0.5 to $3 \mathrm{~mm}$ and intermediate values). The range of values for the controlled process variables were extracted from previous research $[7,9]$. To this end, the full factorial DOE involved 18 experimental combinations. Replications was used to analyse measurement and experimental variance.

To process the 316L stainless steel, we used a Mazak milling centre with a power of $22 \mathrm{Kw}$. In order to limit the need for experimental work, the approach was to fit our experimental work to a fractional factorial DOE, in which only the more promising values for the process parameters were taken into consideration. To this end, the range of values for the controlled variables were extracted from previous experimental work with the lathe as well as 
related research $[9,11]$ and we set the impact frequency to $19,000 \mathrm{~Hz}$. During the milling process, we studied three relevant factors: (1) table feed $(\mathrm{mm} / \mathrm{min})$, side shift $(\mathrm{mm})$ and (2) spring compression ( $\mathrm{mm}$ ). Table feed had 10 levels (i.e. ranging from 300 to $5000 \mathrm{~mm} / \mathrm{min}$ with intermediate values), side shift had 5 levels (i.e. ranging from 0.025 to $0.2 \mathrm{~mm}$ with intermediate values) and spring compression was tested for 6 levels (i.e. ranging from 0.5 to $3.5 \mathrm{~mm}$ with intermediate values). To this end, the DOE involved 54 experimental combinations, from which the most promising experimental combinations were replicated several times.

The burnishing for both materials was performed with the same finishing head, a wolfram-carbide ball with a diameter of $3 \mathrm{~mm}$. The cooling fluid used was a mineral oil-water mixture of $5 \%$ concentration for both experiments (i.e. Co-Cr lather processing and 316L milling processing). A lubrication fluid was utilized to avoid overheating the workpiece. The effect of noise factors, such as external noise (e.g. environmental conditions, temperature and humidity), deterioration noise (e.g. machine lifetime deterioration, machine maintenance and material quality) and variation noise (e.g. tool and machine stiffness and vibrations) was minimized by performing the experiment in a controlled environment.

The analysis of the experimental result was performed using "Minitab 16" statistical software. To this end, the data have been analysed by analysis of variance (ANOVA) and studying the effect and interactions of process parameter on the final surface quality. The results will show the corresponding main effect plots for surface quality, which has been used to model differences between level means at different levels. Finally, the interaction and the impact of the most relevant factors are studied using Pareto charts of the standardized effects. In this case, Pareto chart of the effects will be used to determine the magnitude and the importance of an effect and the effect of the interactions.

\subsection{Measurement setup}

The measurements were focussed on obtaining values for surface roughness $(\mathrm{Ra})$ for each experimental combination and hardness for the most relevant results (Hv10). The surface roughness was measured with a Perthen perthometer M4P measuring device. The device uses a touch probe to measure the topology of a line on the surface. The measurements are in Ra values, which refer to the mean deviation of the surface profile in $\mu \mathrm{m}$. There were three repetitions for each measured surface, three before process and three after process. Unusual values were rejected and measured again. A total number of 45 roughness measurements for $\mathrm{Co}-\mathrm{Cr}$ and 162 for stainless steel 316L were done. The measurement direction of each sample was perpendicular to movement of the tool. In addition, the hardness was measured in three different points in both finished and unfinished surfaces by the Vickers method using a Brickers 220 hardness measuring device. In the hardness measurement of Co-Cr test pieces, the standard SFS EN ISO 6507 1 [23] was used to correct errors in the hardness values due to the cylindricity of the test pieces. This standard provides equations for compensating the cylinder effect.

As a reference and comparison, two surfaces of $\mathrm{Co}-\mathrm{Cr}$ and three surfaces of $316 \mathrm{~L}$ were machined before burnishing to compare how much surface roughness and hardness will differ from directly burnished samples. The milling parameters for $316 \mathrm{~L}$ were $1592 \mathrm{rpm}, 60-\mathrm{mm}$ diameter face mill, 4 teeth, feed $1500 \mathrm{~mm} / \mathrm{min}$, feed per tooth $0.03 \mathrm{~mm}$ and 0.1 for depth of cut. Parameters for $\mathrm{Co}-\mathrm{Cr}$ were $500 \mathrm{rpm}$, feed $0.3 \mathrm{~mm} / \mathrm{r}$ and $0.4 \mathrm{~mm}$ as outer corner radius of the tool.

\section{Results}

\subsection{AM and ultrasonic burnishing post-processing for $\mathrm{Co}-\mathrm{Cr}$}

By analysing statistically the experimental data, we can indicate that optimal process parameters from the tested parameters for post-processing Co-Cr material are around $0.05 \mathrm{~mm} / \mathrm{r}$ for the feed and $1.5 \mathrm{~mm}$ for the spring compression. The main effect for surface quality with different variables is shown in Fig. 4 and the Pareto chart in Fig. 5 is used to describe the most influential process parameter as well as possible interactions between feed and spring compression.

As a summary of the results regarding post-processing options for Co-Cr, Table 1 shows the measured surface quality and hardness, presenting minimum, maximum and average values of as-built $\mathrm{Co}-\mathrm{Cr}$, ultrasonic burnished $\mathrm{Co}-\mathrm{Cr}$, milled $\mathrm{Co}-\mathrm{Cr}$ and milled and burnished $\mathrm{Co}-\mathrm{Cr}$.

The process time in ultrasonic burnishing depends heavily on spindle speed and feed rate. The fasted burnishing time in the tests for Co-Cr was $60 \mathrm{~s}$ and slowest one about $250 \mathrm{~s}$ compared milling time for the same area is $4 \mathrm{~s}$. Table 2 shows the turning processing times with different parameters.

\subsection{AM and ultrasonic burnishing post-processing for stainless steel 316L}

By analysing the experimental data statistically, it can be indicated that the optimal process parameter values from tested ones, when taking consideration productivity, are around $1000 \mathrm{~mm} / \mathrm{min}$ for the feed speed, $0.025 \mathrm{~mm}$ for the side shift and $1 \mathrm{~mm}$ for spring compression for 
Fig. 4 Main effects plot for $\mathrm{Co}-\mathrm{Cr}$

Fig. 5 Pareto Chart for $\mathrm{Co}-\mathrm{Cr}$

Table 1 A summary and comparison of the surface quality and hardness of $\mathrm{Co}-\mathrm{Cr}$
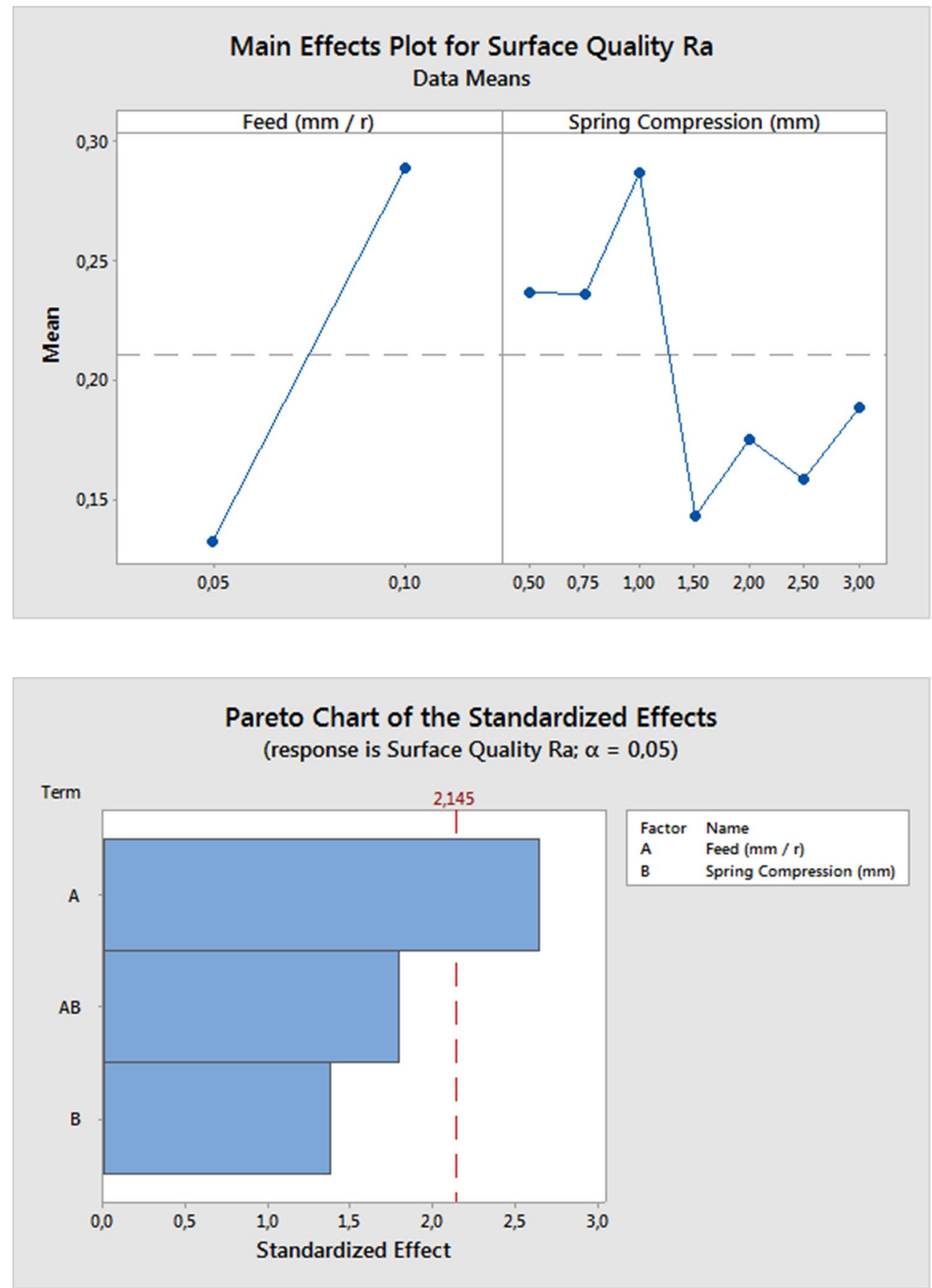

\begin{tabular}{|c|c|c|c|c|c|c|}
\hline & \multicolumn{3}{|c|}{ Surface roughness $\mathrm{Ra}(\mu \mathrm{m})$} & \multicolumn{3}{|c|}{ Hardness (HV10) } \\
\hline & Min & Max & Average & Min & Max & Average \\
\hline As-built $\mathrm{Co}-\mathrm{Cr}$ & 4.30 & 7.81 & 5.66 & 367.04 & 380.63 & 373.84 \\
\hline Ultrasonic burnished $\mathrm{Co}-\mathrm{Cr}$ & 0.08 & 0.2 & 0.18 & 520.78 & 591.02 & 551.07 \\
\hline Turned Co-Cr & 1.20 & 1.26 & 1.24 & 458.64 & 458.64 & 458.64 \\
\hline Turned and burnished Co-Cr & 0.06 & 0.08 & 0.07 & 577.10 & 583.89 & 580.50 \\
\hline
\end{tabular}


Table 2 Process times for $\mathrm{Co}-\mathrm{Cr}$

\begin{tabular}{|c|c|c|c|c|c|c|c|}
\hline \multicolumn{4}{|c|}{ Ultrasonic burnishing } & \multicolumn{4}{|l|}{ Turned } \\
\hline $\begin{array}{l}\text { The area of test } \\
\text { piece }\left(\mathrm{mm}^{2}\right)\end{array}$ & $\begin{array}{l}\text { Spindle speed } \\
(\mathrm{rev} / \mathrm{min})\end{array}$ & $\begin{array}{l}\text { Feed rate } \\
(\mathrm{mm} / \mathrm{rev})\end{array}$ & $\begin{array}{l}\text { The bur- } \\
\text { nishing time } \\
\text { (s) }\end{array}$ & $\begin{array}{l}\text { The area of test } \\
\text { piece }\left(\mathrm{mm}^{2}\right)\end{array}$ & $\begin{array}{l}\text { Spindle speed } \\
\text { (rev/min) }\end{array}$ & $\begin{array}{l}\text { Feed rate }(\mathrm{mm} / \\
\text { rev) }\end{array}$ & $\begin{array}{l}\text { The machining } \\
\text { time (s) }\end{array}$ \\
\hline \multirow[t]{3}{*}{13.7} & 50 & 0.05 & 240 & 13.7 & 500 & 0.3 & 4 \\
\hline & & 0.1 & 120 & & & & \\
\hline & & 0.2 & 60 & & & & \\
\hline
\end{tabular}

post-processing 316L material. With feed $5000 \mathrm{~mm} /$ min, measured values were not reliable since the current construction of the tool started bend and the tip to drag behind. The main effect for surface quality with different variables is shown in Fig. 6 and the Pareto chart in Fig. 7 is used to describe the most influential process parameter as well as possible interactions between side shift, feed and spring compression.

As a summary of the results regarding post-processing options for $316 \mathrm{~L}$ stainless steel, Table 3 shows the measured surface quality and hardness, presenting the minimum, maximum and average values of as-built $316 \mathrm{~L}$, ultrasonic burnished $316 \mathrm{~L}$, milled $316 \mathrm{~L}$, and milled and burnished 316L.
The process time in ultrasonic burnishing depends heavily on spindle speed and feed rate. The fasted burnishing time in the tests for $316 \mathrm{~L}$ was $1 \mathrm{~min}$ and slowest one 17 min compared milling time for the same area is couple of seconds. The process times with different parameters are shown in Table 4.

\section{Discussion}

The lack of empirical research on ultrasonic burnishing applied to the post-processing of AM metallic materials motivated this research; therefore, the effects of process parameters, such as machine and tool relative displacement speeds (i.e. feed speeds and side shift), were initially

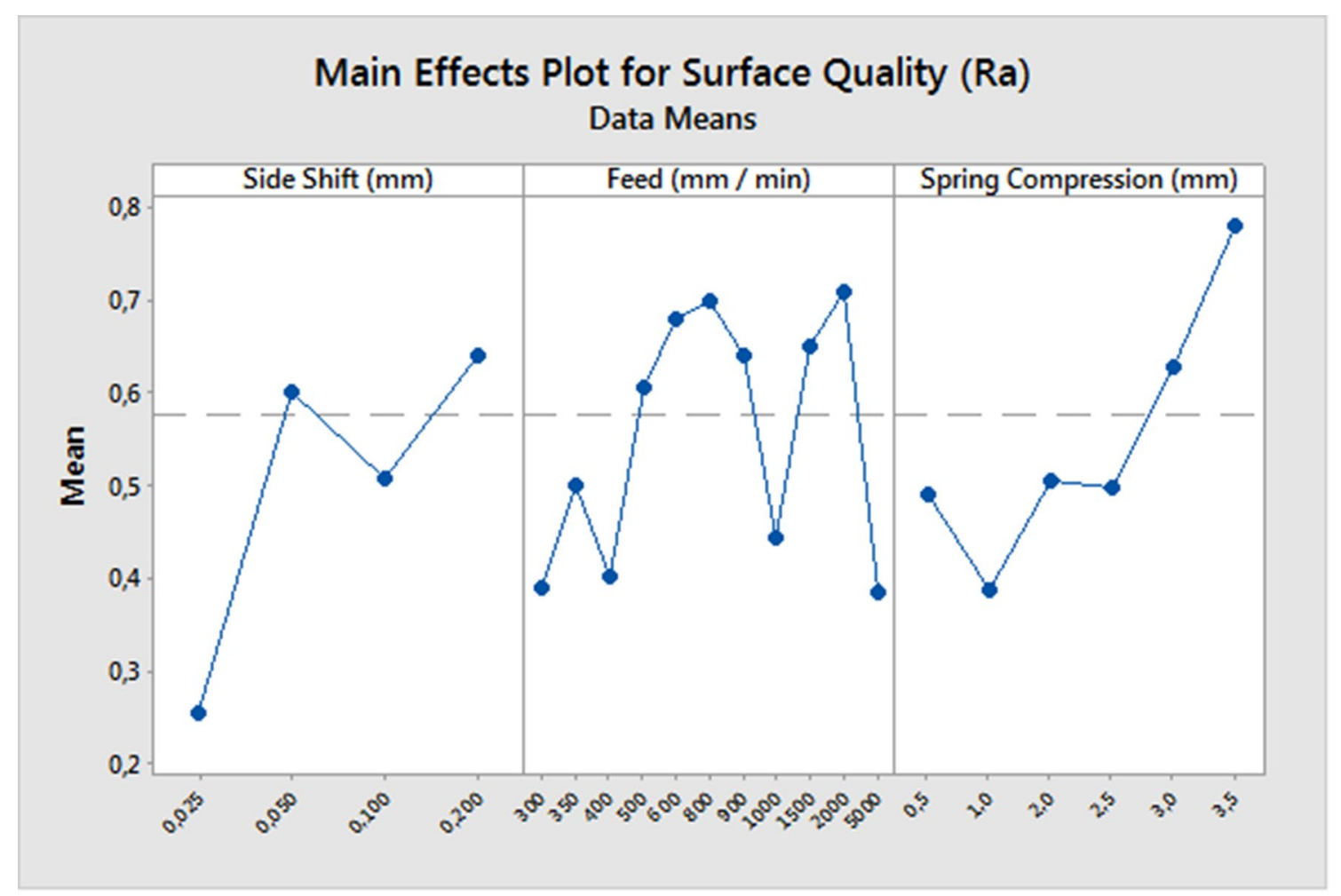

Fig. 6 Main effects plot for 316L 
Fig. 7 Pareto chart for $316 \mathrm{~L}$

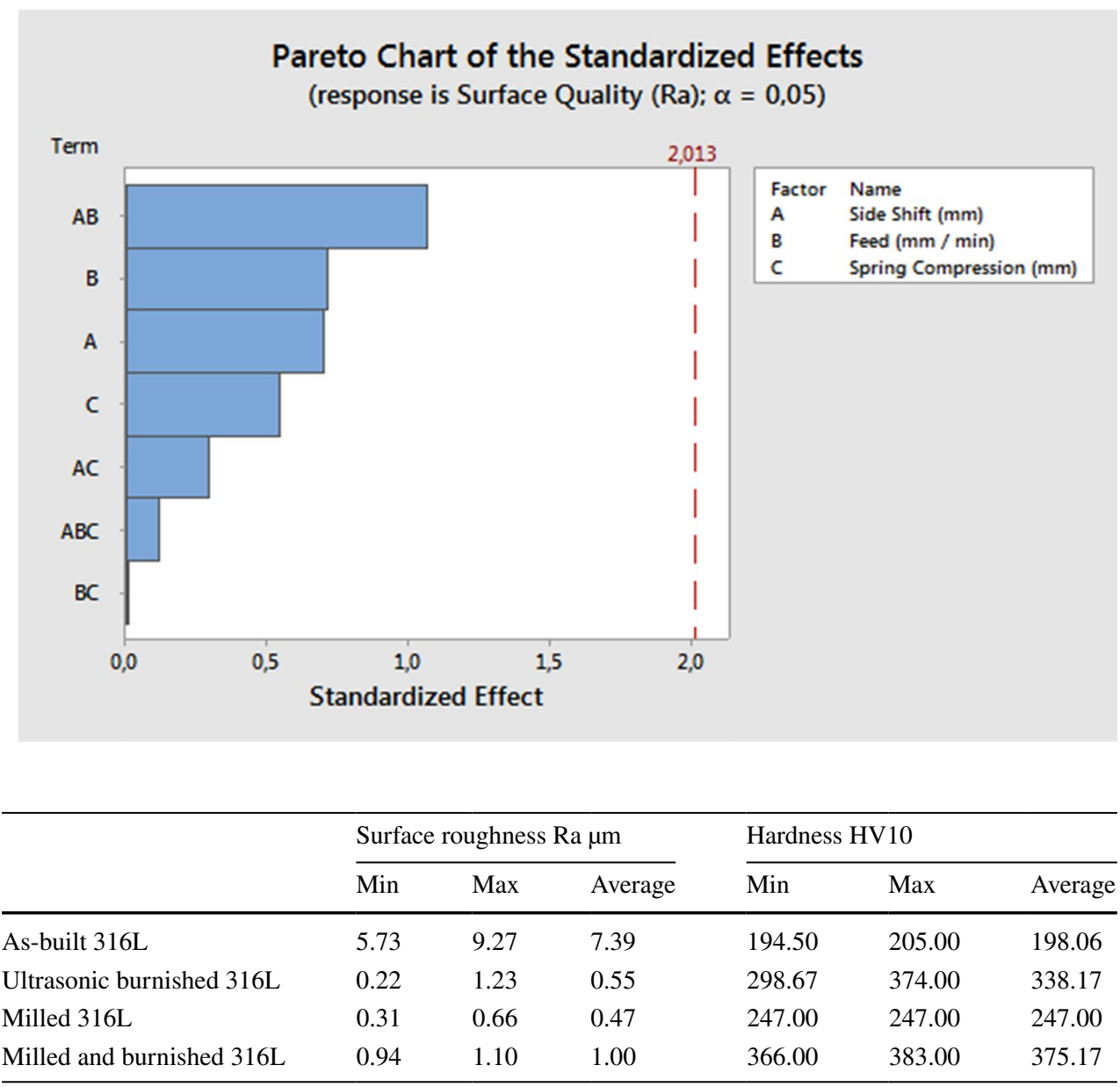

Table 3 A summary and comparison of surface quality and hardness for stainless steel $316 \mathrm{~L}$

\section{Milled}

\begin{tabular}{|c|c|c|c|c|c|c|c|}
\hline \multicolumn{4}{|l|}{ Ultrasonic burnishing } & \multicolumn{4}{|l|}{ Milled } \\
\hline $\begin{array}{l}\text { The area of test piece } \\
\left(\mathrm{mm}^{2}\right)\end{array}$ & Side shift $(\mathrm{mm})$ & $\begin{array}{l}\text { Table feed } \\
(\mathrm{mm} / \mathrm{min})\end{array}$ & $\begin{array}{l}\text { The burnish- } \\
\text { ing time } \\
\text { (min) }\end{array}$ & $\begin{array}{l}\text { The area of test piece } \\
\left(\mathrm{mm}^{2}\right)\end{array}$ & Side shift $(\mathrm{mm})$ & $\begin{array}{l}\text { Table feed } \\
(\mathrm{mm} / \mathrm{min})\end{array}$ & $\begin{array}{l}\text { The } \\
\text { machining } \\
\text { time (s) }\end{array}$ \\
\hline \multirow[t]{4}{*}{105} & 0.025 & 1000 & 17.20 & 105 & 0.1 & 192 & 5 \\
\hline & 0.05 & 1000 & 8.40 & & & & \\
\hline & 0.1 & 1000 & 4.20 & & & 1020 & 1 \\
\hline & 0.1 & 5000 & 0.52 & & & & \\
\hline
\end{tabular}

studied. Furthermore, the effect of spring compression and ultrasonic burnishing frequency on surface quality and hardness was tested. The most relevant variables in the post-processing of AM produced metallic parts were initially mapped and tested in two different experimental manufacturing setups (i.e. Co-Cr lathe processing and $316 \mathrm{~L}$ milling processing), the obtained data served as the ground for the presented analysis.

The results show that the post-processing of AM metallic material, implementing automated ultrasonic burnishing processes, can substantially improve the surface quality of as-built AM metals. Hardness values also improve substantially during the same process. However, optimization of the most relevant process parameters is required to obtain reliable machine setups. Currently ultrasonic burnishing is much slower compared to machining as it can be seen from the results, but in contrast, burnishing can become cost effective in comparison to hand polishing or other manual work. In addition, increased hardness might give better product performance to justify the process. Higher productivity values with a good surface quality and increased hardness can 
be obtained with a better tool construction and minimizing vibrations.

\subsection{The ultrasonic burnishing of $\mathrm{Co}-\mathrm{Cr}$ and its medical applications}

The experimental results presented in Fig. 4 show that surface roughness increases with the increase of feed speed and spring compression need to be not too low or not too high. Therefore, the optimization of these parameters is fundamental to achieve proper values in hardness and surface quality. The empirical evidence indicates that by fixing the feed speed to $0.05 \mathrm{~mm} / \mathrm{rev}$ and having $1.5 \mathrm{~mm}$ of spring compression it is possible to obtain close to optimal results in terms of surface quality.

Looking at the summary of the results presented in Table 1, the post-processing of as-built $\mathrm{Co}-\mathrm{Cr}$ by the ultrasonic burnishing method allowed a relative hardness increase of $47.4 \%$ (i.e. from 373.84 to $551.07 \mathrm{Hv}$ ), whereas (only) milled $\mathrm{Co}-\mathrm{Cr}$ had a relative increase of $22.7 \%$. When comparing ultrasonic burnished $\mathrm{Co}-\mathrm{Cr}$ hardness versus milled and burnished $\mathrm{Co}-\mathrm{Cr}$ (which had a relative increase in hardness of 55.8\%), the difference is not substantial.

Regarding the surface quality improvement achieved in the post-processing of as-built $\mathrm{Co}-\mathrm{Cr}$ by ultrasonic burnishing, Table 1 shows that the surface quality improved approximately 32 times from as-built $\mathrm{Co}-\mathrm{Cr}$ (i.e. from $\mathrm{Ra}=5.66 \mu \mathrm{m}$ to $\mathrm{Ra}=0.18 \mu \mathrm{m})$. Comparing only milled $\mathrm{Co}-\mathrm{Cr}$ and ultrasonic burnished $\mathrm{Co}-\mathrm{Cr}$, the second process achieved better surface quality, with Ra values below $0.2 \mu \mathrm{m}$, which is a high level of finish and a perfectly smooth surface according to production standard ISO 1302:2002. When evaluating the difference of ultrasonic burnished $\mathrm{Co}-\mathrm{Cr}(\mathrm{Ra}=0.18 \mu \mathrm{m})$ versus milled and burnished $\mathrm{Co}-\mathrm{Cr}(\mathrm{Ra}=0.07 \mu \mathrm{m})$, the second process shows better surface quality, but nevertheless, the difference is not substantial as both processes fall under the same category in the ISO standard. In addition, the experimental results show that the most influential process parameter in the $\mathrm{Co}-\mathrm{Cr}$ lathe processing experiment is the feed, the result of the Pareto analysis in Fig. 5 demonstrates that relative displacement of the burnishing ball and the test workpiece become fundamental to achieve optimal values. The interaction between spring compression and feed shows to be more important than the spring compression alone.

Based on this experiment, the post-processing of $\mathrm{Co}-\mathrm{Cr}$ can be exclusively performed by ultrasonic burnishing in order to achieve surface and hardness quality. On the other hand, the milling operation can be limited to support removal. Hence, the ultrasonic burnishing approach could potentially be used for post-processing the Co-Cr dental crowns and bridges made by AM. Previous research has indicated that the finishing of $\mathrm{Co}-\mathrm{Cr}$ dental applications made additively requires machining or the usage of manual dental laboratory equipment and techniques [24]. Typically, dental crowns and bridges made by laser-based AM requires manual finishing effort after $\mathrm{NC}$ milling [25]. Also removable partial denture alloy frameworks need manual polishing [26].

In the proposed solution, an automated process combining an ultrasonic burnishing tool head installed in a NC machine centre can be used to post-process $\mathrm{Co}-\mathrm{Cr}$ in additively produced applications. This process will provide better hardness and good surface quality, improving resistance to abrasion and making it easier to sterilize. In addition, labour-intensive finishing processes can be replaced by setting up a more automated manufacturing system in order to provide a fully digitalized solution for dental applications, as well as other applications.

\subsection{The ultrasonic burnishing of stainless steel 316L and its industrial applications}

The experimental results presented in Fig. 6 show that surface roughness increases with the increase of spring compression as well as table feed speed. In addition, an increase in side shift values also has a negative impact on surface quality. Therefore, optimization of these parameters is fundamental in order to achieve proper values in hardness and surface quality. On the other hand, statistical analysis shows that combined effect from side shift and feed has the most effect to surface quality. Still even this combined effect will not statistically threshold as potentially important. This might be explained that in the process there might be variable that was not taken account enough, such as construction of the tool, vibrations etc. The empirical evidence indicates that by fixing the table feed speed to $1000 \mathrm{~mm} / \mathrm{min}$, the side shift to $0.025 \mathrm{~mm}$ and using a spring compression of $1.5 \mathrm{~mm}$, it is possible to obtain close to optimal results in terms of surface quality and final hardness when also taking productivity in the considerations.

The effect of side shifts on the base roughness of material was relatively insignificant if the tool touches all the areas of the surface. In the experiments presented by López De Lacalle et al. [27], the best results after burnishing were achieved using $0.05 \mathrm{~mm}$ side shifts (Ra $0.18 \mu \mathrm{m}$ ). This value correlates with our experimental results. In addition, one should bear in mind that during ultrasonic burnishing the contact points of the post-processed workpieces should not be deformed too many times in order to ensure good burnishing results, as presented by Korzynski et al. [28].

The results presented in Table 3 show that the postprocessing of $316 \mathrm{~L}$ as-built stainless steel by ultrasonic burnishing method allowed a relative hardness increase of $70.7 \%$ (i.e. from 198.06 to $338.17 \mathrm{Hv}$ ), whereas (only) milled 316L stainless steel had a relative increase of 
24.7\%. When comparing ultrasonic burnished 316L hardness versus milled and burnished $316 \mathrm{~L}$, which had a relative increase in hardness of $89.4 \%$, this second process has better results; however, the difference is only of an $18.7 \%$ gain in hardness.

The surface quality achieved in the post-processing of $316 \mathrm{~L}$ as-built stainless steel by ultrasonic burnishing is presented in Table 3. The results show that surface roughness decreased by approximately 13 times after the ultrasonic burnishing of $316 \mathrm{~L}$ as-built stainless steel (i.e. from $\mathrm{Ra}=7.39 \mu \mathrm{m}$ to $\mathrm{Ra}=0.55 \mu \mathrm{m}$ ). Compared to (only) milled $316 \mathrm{~L}$ and ultrasonic burnished $316 \mathrm{~L}$, the first process achieved better surface quality- $\mathrm{Ra}=0.47 \mu \mathrm{m}-$ whereas burnished $316 \mathrm{~L}$ had an average surface roughness of $\mathrm{Ra}=0.55 \mu \mathrm{m}$. Nevertheless, the difference is minimal and both finishing strategies would fall under the same category of extra fine finish for machine tools, according to production standard ISO 1302:2002 [25]. When evaluating the difference of ultrasonic burnished 316L $(\mathrm{Ra}=0.55 \mu \mathrm{m})$ versus milled and burnished $\mathrm{Co}-\mathrm{Cr}$ $(\mathrm{Ra}=1 \mu \mathrm{m})$, the second process shows poorer surface quality. This counterintuitive effect can be explained due to the use of the same parameters for both post-process 316L and milled 316L. The experimental results show that the optimal process parameters need to be different post-process for milled 316L with ultrasonic burnishing. In addition, the experimental results show that the most influential process parameter in the $316 \mathrm{~L}$ milling processing experiment is the interaction between feed speed and side shift, the result of the Pareto analysis in Fig. 7 demonstrates that the milling path becomes critical to achieve optimal values. Consistently, with existing body of research [23] as well as the previous experimental approach with $\mathrm{Co}-\mathrm{Cr}$, the most influential parameter in this experiment is the relative displacements of the burnishing tool and the workpiece followed by the spring compression.

The implementation of ultrasonic burnishing to postprocess additively produced tool inserts could remarkably increase the surface hardness as well as the surface quality of the produced parts. Therefore, a tool insert located in the hot spots of forming tools will also increase wear resistance as well as fatigue life. Typically, milling postprocessing can achieve specified high-quality roughness as long as the quality cutting tools and fluids are optimized. However, a high finish in milling requires that the end tool is changed periodically, whereas in the ultrasonic burnishing process the carbide ball has longer lifetime. AM-produced and ultrasonically burnished tool inserts have the potential to increase the performance of the forming process, as well as to reduce costs, when AM parts can be finished without machining, shortening working time.

\section{Conclusions}

Previous research has shown that the surface integrity of the material can be improved by ultrasonic burnishing processes [4]. The method has been used in a variety of materials to improve mechanical properties as well as to decrease surface roughness and increase surface hardness. However, the ultrasonic burnishing of additively produced metals and its possible applications have not been presented to date. This paper is the first attempt to research how ultrasonic burnishing post-processing methods impact on the surface roughness and hardness of AM metal components.

This work helps in understanding how the method affects the surface roughness and hardness of AM metallic materials. Judging by the experimental work presented in this article, ultrasonic burnishing improves the surface quality of metal AM parts: surfaces roughness improved remarkably and the surface hardness increases after burnishing. The experimental results confirmed the effectiveness of the ultrasonic burnishing method for enhancing the surface treatment with AM parts. The following conclusions can be drawn:

1. After ultrasonic burnishing, the average surface roughness (Ra) of $\mathrm{Co}-\mathrm{Cr}$ was 0.18 and $0.55 \mu \mathrm{m}$ for $316 \mathrm{~L}$ stainless steel.

2. After ultrasonic burnishing, the relative increase in the average hardness of Co-Cr was $47.4 \%$ (i.e. $551.07 \mathrm{Hv}$ ) and $70.7 \%$ for $316 \mathrm{~L}$ stainless steel (i.e. $338.17 \mathrm{Hv}$ ).

3. Optimal process parameters for post-processing $\mathrm{Co}-\mathrm{Cr}$ material are around $0.05 \mathrm{~mm} / \mathrm{r}$ for the feed and $1.5 \mathrm{~mm}$ for the spring compression.

4. Optimal process parameter for post-processing 316L material is around $1000 \mathrm{~mm} / \mathrm{min}$ for the feed speed, $0.025 \mathrm{~mm}$ for the side shift and $1 \mathrm{~mm}$ for spring compression, when taking also productivity into consideration.

The results of this experiment point out that ultrasonic burnishing increases surface quality and surface hardness remarkably, also showing better results compared with the typical milling post-processing techniques used in the industry. This research was limited to study the side surfaces of the additively manufactured parts. Typically, the as-built top surface parts have better surface quality and the bottom surface requires support removal. Nevertheless, the effect of build orientation and the staircase effect in AMproduced parts can also be minimized by implementing an automated ultrasonic burnishing post-process. This could also reduce the labour-intensive processes of finishing metal parts made by AM processes and reduce cost barriers to the applications of additive technologies. 
To conclude, future research need to focus on finding optimal burnishing process parameters considering the trade-offs between technical parameters (e.g. surface quality and surface hardness) and productivity issues (e.g. decrease manufacturing time) to drive this technologies to real industrial applications. To do so, more DOEs are planned to study the sensitivity of relevant process parameters (i.e. spring force, impact frequency, the effect of lubrication, feed speed, side shift, revolutions and the tool path of burnishing processes). In addition, the effect of noise factors (i.e. external noise, deterioration noise and variation noise, vibrations, construction of the tools) and trade-off over response variables (i.e. surface roughness and micro-hardness) had to be studied further. The industrial automation of ultrasonic burnishing post-processing for application in Co-Cr dental applications, as well as the post-processing of additively produced stainless steel for tool inserts, needs to be researched empirically in order to define technical parameters and drive the adoption of novel manufacturing methods based in additive processes in the industry.

\section{Compliance with ethical standards}

Conflict of interest On behalf of all authors, the corresponding author states that there is no conflict of interest.

\section{References}

1. Jürgen Gausemeier, Niklas Echterhoff MW (2013) Thinking ahead the future of additive manufacturing-innovation roadmapping of required advancements. Heinz Nixdorf Institute, Paderborn

2. Flores Ituarte I, Partanen J, Khajavi SH (2016) Challenges to implementing additive manufacturing in globalised production environments. Int J Collab Enterp 5:232-247

3. Flores Ituarte I, Coatanea E, Salmi M et al (2015) Additive manufacturing in production: a study case applying technical requirements. Phys Procedia 78:357-366. doi:10.1016/j. phpro.2015.11.050

4. Horizon2020 FP7 (2014) Additive manufacturing in FP7 and Horizon 2020. Report from the EC Workshop on Additive Manufacturing held on 18 June 2014. European Commission

5. Farayibi PK, Abioye TE, Murray JW et al (2015) Surface improvement of laser clad Ti-6Al-4 V using plain waterjet and pulsed electron beam irradiation. J Mater Process Technol 218:1-11. doi:10.1016/j.jmatprotec.2014.11.035

6. Mahajan D, Tajane R (2013) A review on ball burnishing process. Int J Sci Res Publ 3:1-8

7. Hocheng H, Kuo KL (2002) Fundamental study of ultrasonic polishing of mold steel. Int $\mathbf{J}$ Mach Tools Manuf 42:7-13. doi:10.1016/S0890-6955(01)00099-2

8. Hassan AM, Al-Bsharat AS (1996) Influence of burnishing process on surface roughness, hardness, and microstructure of some non-ferrous metals. Wear 199:1-8. doi:10.1016/0043-1648(95)06847-3

9. Huuki J, Laakso SV (2012) Integrity of surfaces finished with ultrasonic burnishing. Proc Inst Mech Eng Part B J Eng Manuf 227:45-53. doi:10.1177/0954405412462805
10. Han C-H, Pyoun YS, Kim CS (2002) Ultrasonic micro-burnishing in view of eco-materials processing. Adv Technol Mater Mater Process J 4:25-28

11. Huuki J, Hornborg M, Juntunen J (2014) Influence of ultrasonic burnishing technique on surface quality and change in the dimensions of metal shafts. J Eng 2014:5-7

12. Bozdana a. T, Gindy NNZ, Li H (2005) Deep cold rolling with ultrasonic vibrations-a new mechanical surface enhancement technique. Int J Mach Tools Manuf 45:713-718. doi:10.1016/j. ijmachtools.2004.09.017

13. El-Khabeery MM, El-Axir MH (2001) Experimental techniques for studying the effects of milling roller-burnishing parameters on surface integrity. Int J Mach Tools Manuf 41:1705-1719. doi:10.1016/S0890-6955(01)00036-0

14. Van Noort R (2012) The future of dental devices is digital. Dent Mater 28:3-12. doi:10.1016/j.dental.2011.10.014

15. Vandenbroucke B, Kruth J-P (2007) Selective laser melting of biocompatible metals for rapid manufacturing of medical parts. Rapid Prototyp J 13:196-203. doi:10.1108/13552540710776142

16. Guo N, Leu MC (2013) Additive manufacturing: technology, applications and research needs. Front Mech Eng 8:215-243. doi:10.1007/s11465-013-0248-8

17. Nagahanumaiah BR (2009) Effects of injection molding parameters on shrinkage and weight of plastic part produced by DMLS mold. Rapid Prototyp J 15:179-186. doi:10.1108/13552540910960271

18. Abe F, Osakada K, Shiomi M et al (2001) The manufacturing of hard tools from metallic powders by selective laser melting. J Mater Process Technol 111:210-213. doi:10.1016/ S0924-0136(01)00522-2

19. Lyons B (2012) Additive manufacturing in aerospace examples and research outlook. Front Eng 42:13-19.

20. Wilson JM, Piya C, Shin YC et al (2014) Remanufacturing of turbine blades by laser direct deposition with its energy and environmental impact analysis. J Clean Prod 80:170-178. doi:10.1016/j.jclepro.2014.05.084

21. Flores Ituarte I, Chekurov S, Salmi M et al (2015) Post-processing opportunities of professional and consumer grade 3D printing equipment: a comparative study. Int J Rapid Manuf 5:58-75

22. EOS GmbH-Electro Optical Systems (2014) Material data sheets EOS StainlessSteel 316L and Cobalt Chrome SP2. Available at http://www.eos.info

23. ISO 1302 (2002) Geometrical Product Specifications (GPS)indication of surface texture in technical product documentation, 4th edn. International Organization for Standardization

24. Zandparsa R (2015) Digital imaging and fabrication. Dent Clin 58:135-158. doi:10.1016/j.cden.2013.09.012

25. Gebhardt A, Schmidt FM, Hötter JS, et al (2010) Additive manufacturing by selective laser melting: the realizer desktop machine and its application for the dental industry. Phys Procedia 5:543549. doi:10.1016/j.phpro.2010.08.082

26. Bibb R, Eggbeer D, Williams R (2006) Rapid manufacture of removable partial denture frameworks. Rapid Prototyp J 12:9599. doi:10.1108/13552540610652438

27. López De Lacalle LN, Lamikiz a., Muñoa J, Sánchez J a (2005) Quality improvement of ball-end milled sculptured surfaces by ball burnishing. Int J Mach Tools Manuf 45:1659-1668. doi:10.1016/j.ijmachtools.2005.03.007

28. Korzynski M, Lubas J, Swirad S, Dudek K (2011) Surface layer characteristics due to slide diamond burnishing with a cylindrical-ended tool. J Mater Process Technol 211:84-94. doi:10.1016/j.jmatprotec.2010.08.029 